TITLE:

\title{
Dipole of Centrosymmetric Dimer of Fatty Acid: Limitation of the Vector Sum Law(Dissertation_全文 )
}

$\operatorname{AUTHOR}(\mathrm{S})$ :

Kita, Yasuo

\section{CITATION:}

Kita, Yasuo. Dipole of Centrosymmetric Dimer of Fatty Acid: Limitation of the Vector Sum Law. 京都大学, 1987, 理学博士

\section{ISSUE DATE:}

1987-07-23

URL:

https://doi.org/10.14989/doctor.r6287

RIGHT: 
学位申請論文

喜多保夫 


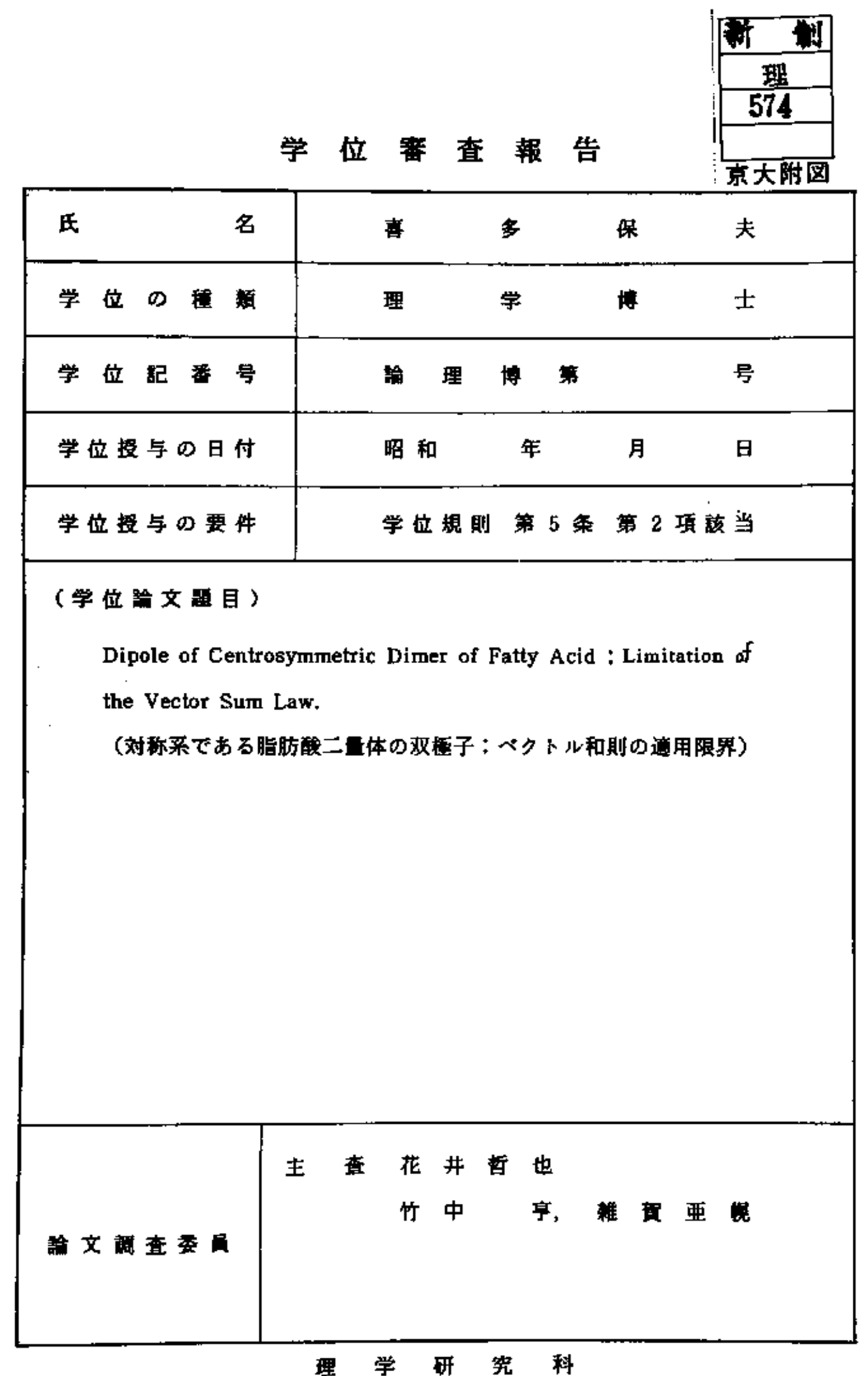




\section{氏名意多保夫}

\section{(影文内容の要旨)}

一般化対称な分子あるい仕分子系は，ペクトル和則に上り電匃双植子を特たず，

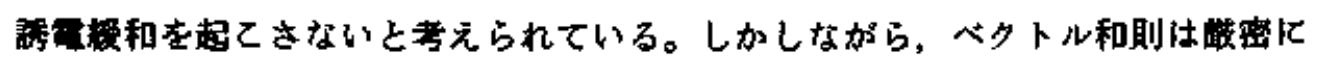

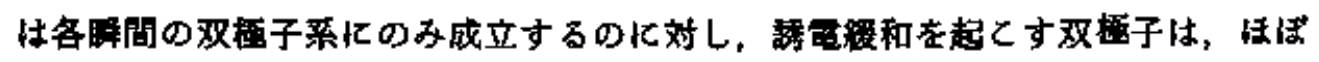

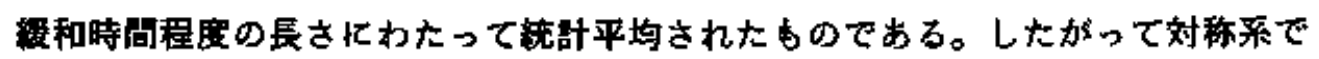

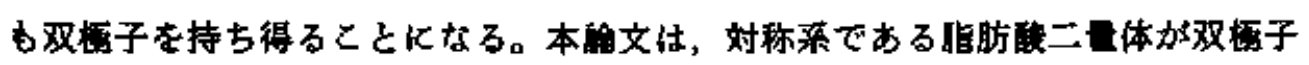

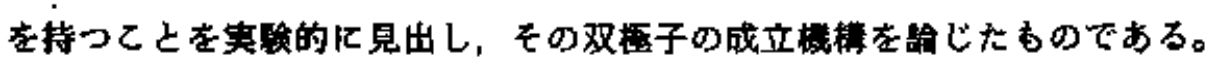

申䛴者は, undecanoic acid, tridecanoic acid, pentadecanoic acid, (以上, 奇数脂仿酸) dodecanoic acid, tetradecanoic acid, hexadecanoic acid，(以上，

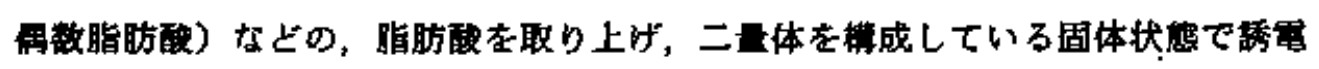

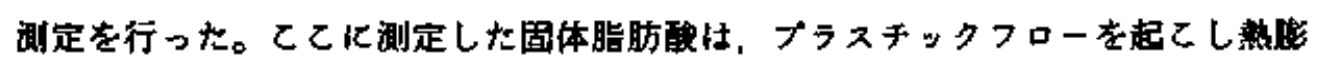

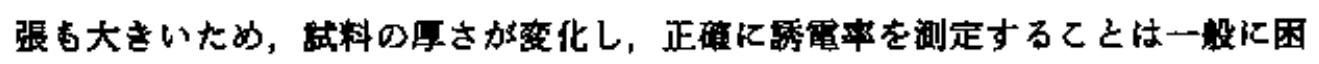

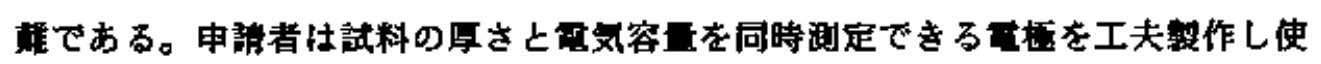

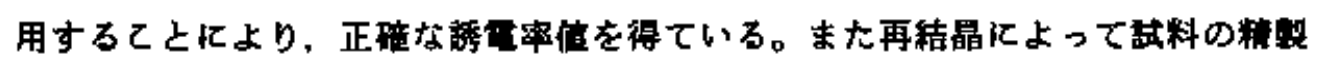

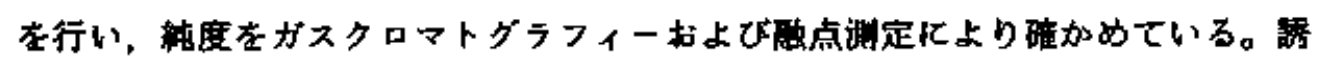

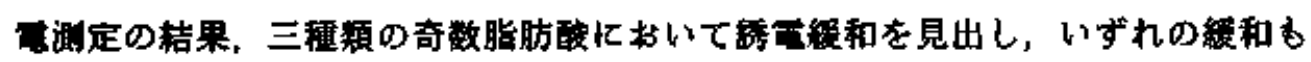

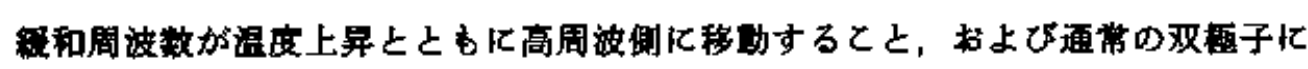

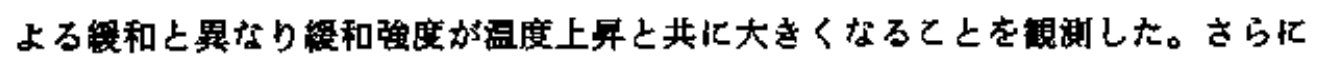

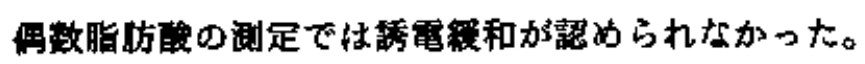

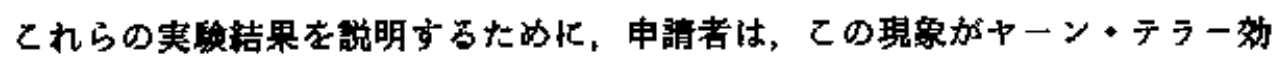
果に上るものではないと考元，次の上うな双極子生成機梳を提案している。個々

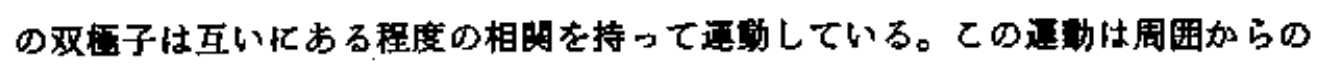

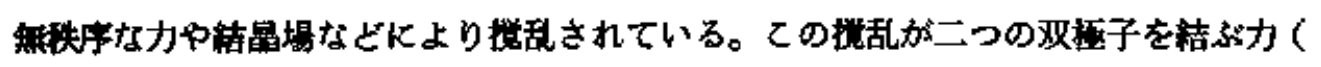

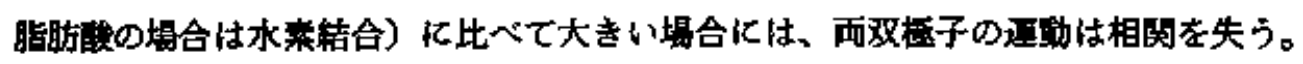

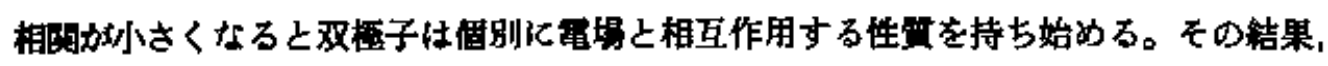
系全体としては双梅子モーメントを生じる。さらに，との考えを定昷化し，立式して，

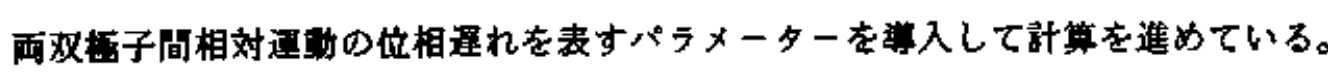




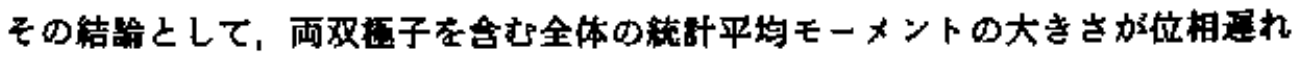

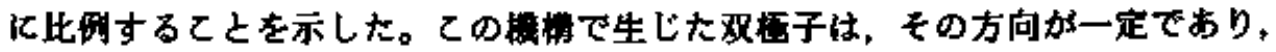

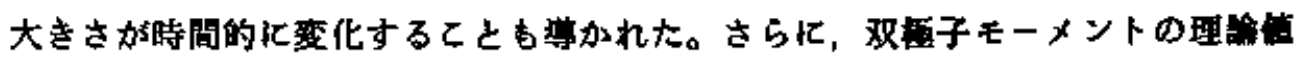

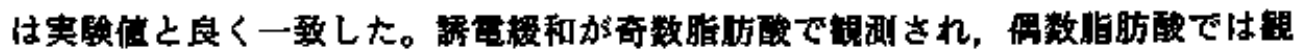

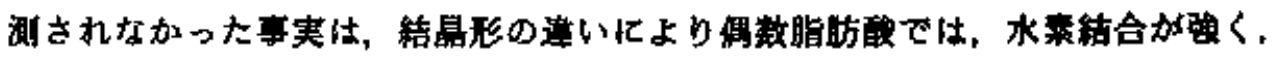

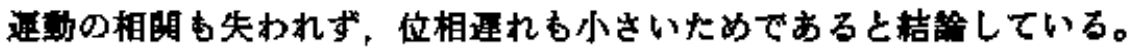

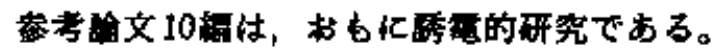




\section{氐名要多保夫}

\section{（鲜文要古の䊅果の要旨）}

対称な分子系权枢子を持たないと考えられている。しかし，分子系が内部的 に㯰野している場合には，ての考えは必ずしも成り立たない。本諭文において申

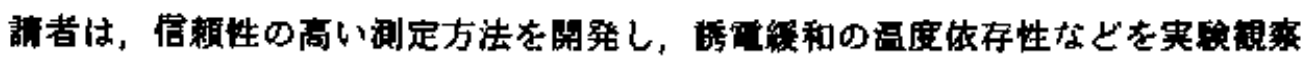

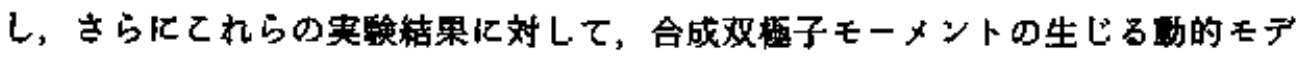

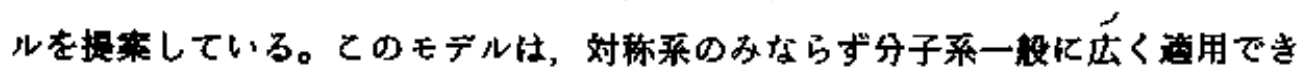
るものであり，分子，原子遇動の研究を大きく進展させることが期待でる。

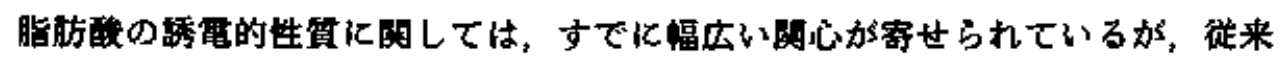

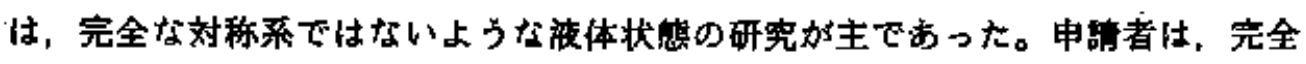

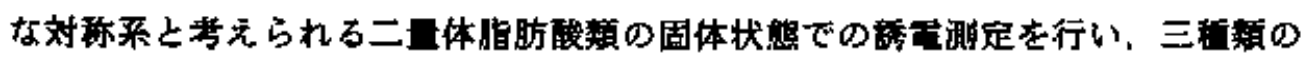

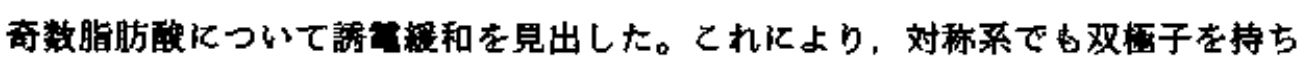

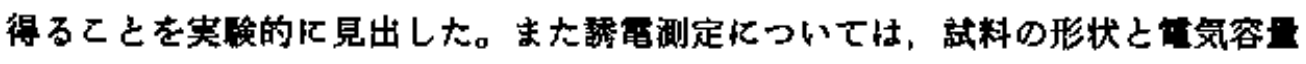

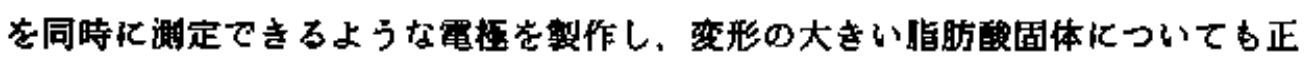

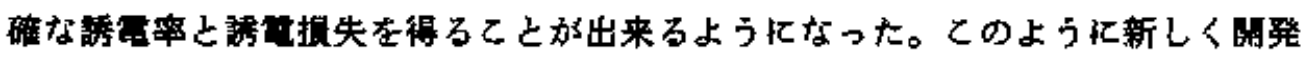

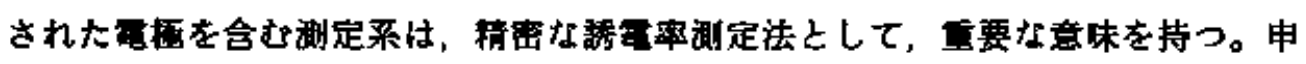

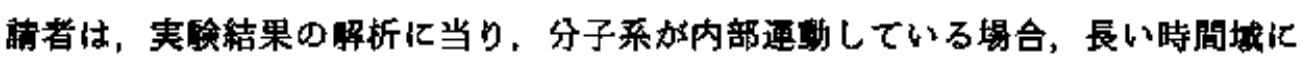
対しては、ベクトル和則が成立しないことを理峆的に明らかにした。これを推し

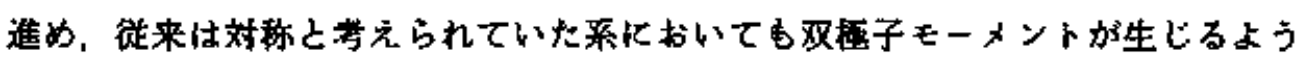
なモテルを提案した。このモデルは，ヤーン・テラー奻果情るものではなく，

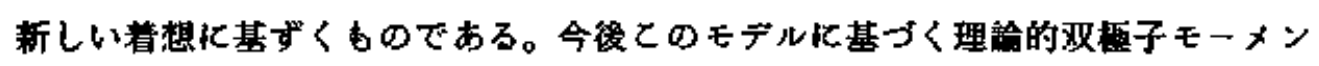

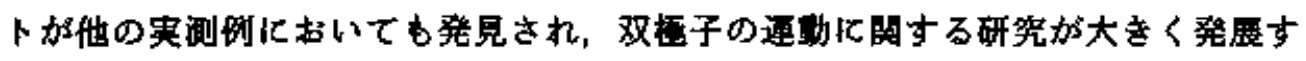

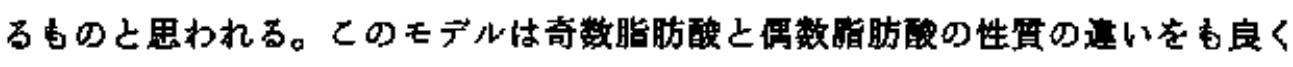

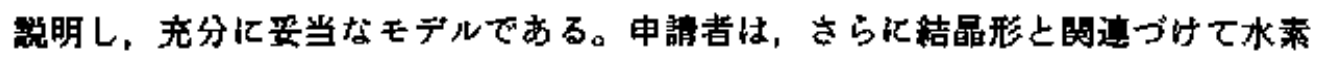

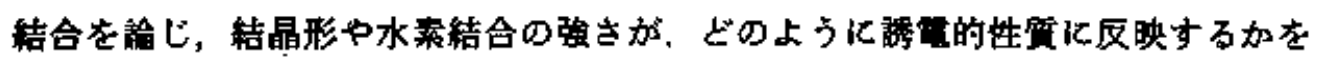
明らかにした。とのことにより，水菜結合の研究に対しても值值ある㝒与をなし ている。

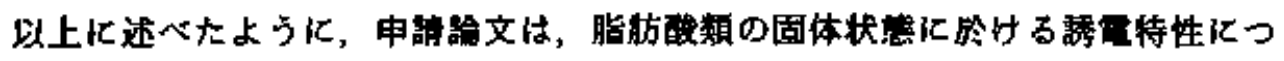




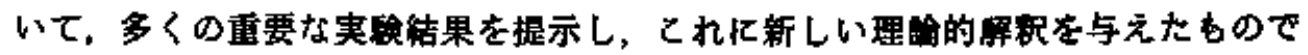
あり，当敦研究分野に蒔与するよころは大きい。

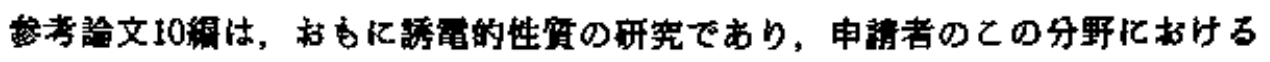
废い学武を示すものである。

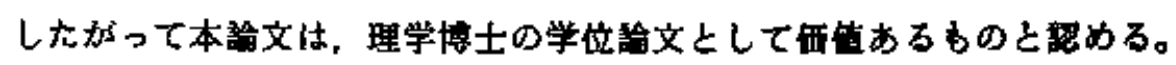

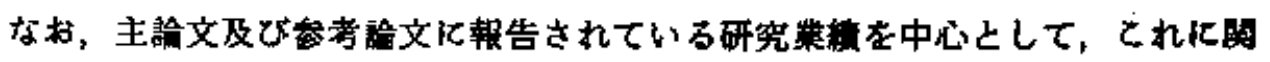
望した研究分野について試䦓した轱果，合格と認める。 
Dipole of Centrasymmetric Dimer of Fatty Acid: Limitation of the Vector Sum Law.

\author{
Yasuo Kita
}

Institute for Chemical Research, Kyoto University, Uji, Kyoto-fu, 611, Japan

Dielectric relaxations were found in the centrosymmetric systemis of the odd numbered fatty acid dimers of undecanoic, tridecanoic, and pentadecanoic acids, while not detected in even numbered acid dimers of lauric, myristic and palmitic acids. These dielectric relaxations suggest that the dipole of a symmetric system is not always zero, though the fatty acid dimers have been assumed to possess no dipole because of the existence of a center of symmetry. It is shown that the vector sum law for electric dipoles has a limitation. A model having the dipole caused by phase shift between rotational motions of two anti-parallel dipoles in the symmetric dimer was proposed. The phase shift is produced by random forces of neighboring dimers, when the forces are strong enough in comparison with the hydrogen bond strength in the dimer. In the proposed model, the dipole is expressed by a single parameter of the phase shift and changes its magnitude but not its direction. The difference in dielectric properties between odd and even numbered acids was explained by the difference in strength of hydrogen bonds which was strongly correlated with the crystal packing. The strong hydrogen bond, which correlates to the $C$-form crystal packing, of even numbered acids forms no net dipole cancelling the two anti-parallel dipoles each other. However, the hydrogen bond of odd numbered acids are veak owing to the different crystal packing. In the weak hydrogen bond the monomeric movement in the dimer can be caused by the strong disturbance and derives a dipole in the symetric dimer unit. 


\section{Introduction}

The Stark effect abserved in $T_{d}$ symmetric methane molecule $e^{1,2}$ shows that a permanent or a long life dipole exists in some symmetric molecules and suggests that the vector sum law for the dipole has some limitation. The dielectric study of dipole detection in symnetric system is necessary to examine the limitation of the vector sum law for the dipole. The mechanisa proposed by Mizushina and Venkateswarlu $u^{3}$ ( one kind of the Jahn-Teller effect) for the dipole formation in a $T_{d}$ symmetric molecule can not be applied to that in the $\mathrm{C}_{2 \mathrm{~h}}$ symmetry system as proved by Mills, Watson, and Smith. Though the theory of Mizushima and Venkateswarlu is valid for an isolated molecule in gaseous phase, the atomic motions in a molecule are disturbed in condensed phase with random forces from the neighboring molecules and the $\mathrm{C}_{\mathrm{h}}$ symmetry molecule may have a dipole as a consequence. The search of dipoles in $\mathrm{C}_{3}$ symmetry such as fatty acid dimer is desired for the check of limitation of vector sum law. Several investigations $5,6,7$ on the dielectric properties of liquid fatty acids suggest the existence of the dipole, though the liquid fatty acids are almost completely associated into dimers. However, these investigations did not discuss on the limitation of vector sum law for the dipole. Smyth and Rogers ${ }^{5}$ observed the anomaly that the permittivity of liquid acetic acid increases with increasing temperature and they ascribed the anomaly to the monomer-dimer equilibrium. The idea that the fatty acid dimer unit possesses a dipole was first introduced by Harris and Alder ${ }^{B}$ with the ion pair model. Later Loveluck ${ }^{7}$ discarded the ion pair model which yielded abnormally large dipole moment as vell as activation energy. He estimated the dipole moment of n-caproic acid dimer as $0.7 \mathrm{D}$, but the origin of dipole was not sufficiently explained. Fatty acids in solid state form the dimers completely and those crystal structures are well known, ${ }^{8,9}$ whereas in liquid state the dimer formation is incomplete. The detection of a dielectric relaxation in solid fatty acids proves the existence of a dipole in a perfect dimer. Dielectric properties of solid fatty 
acids have been little measured. Since the specinen thickness varies ${ }^{\prime 0}$ considerably owing to the plastic flow and the large thermal expansion of the substance, it is hard to estimate the thickness and consequently the permittivity accurately. The dielectric cell constructed by McCammon and Work ${ }^{11}$ and improved by the author ${ }^{12}$ is designed for the in situ measurenent of the specimen thickness and thus suitable to measure the dielectric properties of fatty acid plastic crystal. The purpose of this work is to detect the dipole in the $\mathrm{C}_{2 \mathrm{~h}}$ symmetric system and to discuss the origin of the dipole. The difference in physical properties between odd and even numbered fatty acids may give some hints to the origin of the dipole. The odd numbered acids show reversible phase transitions ${ }^{8}$ of the form $C^{\prime} \rightarrow A^{\prime}$ for tridecanoic acid and the form $C^{\prime} \leftrightarrow B^{\prime}$ for undecanoic and for pentadecanoic acid, while the even numbered acids keep a single phase ${ }^{g}$ ( the C-form) in a wide temperature range. The strength of the hydrogen bond changes considerably with the crystalline phase. The difference in the hydrogen bond may give the difference in the dielectric properties of solid fatty acids, showing the possibility of the dipole in a symuetrical dimer unit. 


\section{Experimental.}

Commercial reagents of undecanoic acid $\mathrm{C}_{10} \mathrm{H}_{21} \mathrm{COOH}$, tridecanoic acid $\mathrm{C}_{12} \mathrm{H}_{25} \mathrm{COOH}$, pentadecanoic acid $\mathrm{C}_{14} \mathrm{H}_{29} \mathrm{COOH}$, lauric acid $\mathrm{C}_{11} \mathrm{H}_{23} \mathrm{COOH}$, myristic acid $\mathrm{C}_{13} \mathrm{H}_{27} \mathrm{COOH}$, and palmitic acid $\mathrm{C}_{15} \mathrm{H}_{31} \mathrm{COOH}$ were purified by recrystallization over seven times from methanol or $\mathrm{n}$-hexane. The specimens were dried in vacuum for several hours and kept in dry nitrogen. The purities of these acids over $99.8 \%$ were checked by melting point and gas chromatography. Although voids were frequently introduced into the sample at the sample setting in the dielectric cell, these voids can be removed by the plastic flow of the compounds ${ }^{12}$ as follows. The cell, in which the sample was weakly stressed, was kept just below the melting point over three weeks till no permittivity change was observed for a day. The permittivity and the specimen thickness were measured simultaneously with the dielectric cell described before ${ }^{12}$ by the use of a YHP Co. 4274A LCR meter and an Ando Electric Co. TR-10 transformer bridge. Extremely low loss of pentadecanoic acid was measured by a General Radio Co. 1616 transformer bridge. The cryostat has been described before. ${ }^{12}$ The cooling rate was $0-0.07 \mathrm{Ks}^{-1}$ and the heating rate $0-0.03 \mathrm{Ks}^{-1}$. After the dielectric measurement the orientation of the crystal axis was determined by the X-ray diffraction for the samples on the electrode with a Rigaku Denki Co. RU-3 X-ray diffractometer. Numerical calculations vere carried out with a Facom $M-380-Q$ Computer in the Institute and a Facom M-332 Computer in the Data Processing Center of Kyoto University. 


\section{Results}

Dielectric relaxations vere observed from $150 \mathrm{~K}$ to $250 \mathrm{~K}$ in the low temperature phase for odd numbered fatty acids of undecanoic, tridecanoic, and pentadecanoic acid as shown in Figures 1-3. Figure 1 denonstrates the plots of the imaginary parts of relative permittivity against frequency for the $B^{\prime}$-form ${ }^{8}$ of undecanoic acid around $210 \mathrm{~K}$ where dielectric relaxation is clearly seen. No difference was observed between heating and cooling processes. The relaxation intensity, which was estimated with the loss data, ${ }^{13}$ increases with temperature. Dipole moments of the relaxation estimated using Onsager's equation ${ }^{14}$ are shown in Table I. Figure 2 represents the plots of the imaginary parts of relative permittivity against frequency for the $A$-form of tridecanoic acid around $170 \mathrm{~K}$. Dielectric relaxation was also observed. The dipole moments deternined as above are also listed in Table I. Figure 3 displays the imaginary parts for the $B^{\prime}$-form of pentadecanoic acid around $220 \mathrm{~K}$. Dielectric relaxation is observed, al though the relaxation intensity was too small to determine the dipole moment for pentadecanoic acid.

Real parts of relative permittivities of add numbered acids in the temperature range from liquid nitrogen temperature to the melting point are given in Figures 4-6. The values of relative permittivities below $200 \mathrm{~K}$ were alnost constant around 2.27 for the $B^{\prime}$-form of undecanoic acid, 2.33 for the $A^{\prime}$-form of tridecanoic acid, and 2.34 for the $B^{\prime}$-form of pentadecanoic acid as seen in Figures 4, 5 and 6 , respectively. The change of the peruittivities was reversible in the cooling or heating cycle in this low temperature region. Around the transition temperature, the permittivity of undecanoic acid increased discontinuously at $281 \mathrm{~K}$ on cooling and decreased at $291 \mathrm{~K}$ on heating. The permittivity of tridecanoic and pentadecanoic acid decreased opposite to that of the undecanoic acid at $292 \mathrm{~K}$ and $306 \mathrm{~K}$ on cooling, respectively and increased at $306 \mathrm{~K}$ and $319 \mathrm{~K}$ on heating. respectively. Thermal hysteresis loops were observed around the transition 
temperature. The frequency dependence of the permittivity near the respective transition temperatures may be explained by the Curie-von Schweidler law. ${ }^{16}$

Real parts of relative permittivities for the $C$ form of even numbered acids from liquid helium temperature to the melting point are given in Figures 7-9. The permittivity of lauric acid decreases from 2.8 to 2.4 by cooling or increases by heating as seen in Figure 7. The permittivities are a little larger than the Gough ${ }^{*}$ results. ${ }^{17}$ The value in heating process is almost constant in the temparature range from $80 \mathrm{~K}$ to $250 \mathrm{~K}$, but increases in higher temperature range over $250 \mathrm{~K}$ and eventually returns to the original value 2.8 before cooling. The thermal hysteresis loop was observed. The permittivities of the C-form of myristic acid or that of palnitic acid were almost constant about 2.50-2.55 or 2.41-2.43, respectively, as shown in Figures 8 and 9 , though thermal hysteresis loops were again observed in the magnified scale. The dispersions of the Curie-von Schweidler law were also observed several tens of degrees below the melting points. The dielectric relaxations found in the low temperature phase of odd numbered acids were not abserved in even numbered acids. After the dielectric measurement the sample sticked solidly to the electrodes. When an electrode vas separated from the sample after many attempts, the X-ray diffraction of the sample on the other electrode gave very strong (OOl) reflections and very reak (110) reflection. suggesting that the crystalline ab-plane was perpendicular ( c-axis was nearly parallel) to the electric field. 


\section{Discussion}

Origin of the dipole. A mechanism is discussed to cause the dielectric relaxation found in a centrasymmetric system. The dielectric relaxation intensities due to polar inpurities should decrease ${ }^{18}$ with temperature. Since the relaxation intensities observed in the $C_{2 h}$ symmetric system of odd numbered acid dimers increase with temperature, the dielectric relaxations are not due to a polar impurity such as water. We propose a model that the symmetric dimer itself passesses a dipole. The dipole derived theoretically by Mizushima and Venkateswarlu $u^{3}$ in a symmetric system can not ${ }^{4}$ exist in the $C_{2 h}$ fatty acid dimer. In the model a dipole arises from a different mechanism from Mizushima and Venkateswarlu's theory. The one dimer approximation is adopted i.e. one dimer is isolated in the continuous medium and the atomic motions within the dimer are specified by random and interatomic forces in the crystal field. A model calculation is performed for the dipole moment per dimer unit and the dielectric properties of the substance are determined by an average of dimer ensemble. Three states of the dimer are considered as follows: If the monomer-monomer interaction in a dimer unit is very strong ( a perfect dimer state), one monomer can not move independently of the other monomer. Though the dipole can be instantaneously induced in the dimer, the dipole averaged during a long period is zero. The dielectric relaxation can not be observed in this case, because the dielectric relaxation is caused by the averaged dipole. If the monomer-monomer interaction is negligible( a perfect monomer state), a monomer moves independently of the other to cause the dielectric relaxation by its permanent dipole. If the monomer-monomer interaction is moderate (a quasi-dimer state), the dimer possesses a smaller dipole monomer, because of the non-correlated motion of the mononer unit. The fatty acids under investigation seem to be in the quasi-dimer state specified by the moderate nonomer-monomer interaction.

Figure 10 illustrates the directions of monomer dipoles at an instant in the 
molecule(dimer)-fixed Cartesian coordinates. Capital letters of $\mathrm{C}, \mathrm{H}$, and $\mathrm{O}$ denote the average positions of atoms in equilibrium. The $z$ axis is defined to be parallel to the long axis of dimer. The $x-z$ plane is in the carboxylic ring plane. The dipole $\mu_{1}$ of the monomer 1 at an instant crosses the $z$ axis at an angle $\theta_{1}$ and the projection of $\mu_{1}$ on the $x-y$ plane forms an angle $\varphi_{1}$ with $x$ axis. The direction of the dipole $\mu_{2}$ of the monomer 2 is defined as the same. The dipoles $\mu_{1}$ and $\mu_{2}$ are expressed as

$$
\begin{aligned}
& \mu_{1}=\mu\left(\sin \theta_{1} \cos \varphi_{1}, \sin \theta_{1} \sin \varphi_{1}, \cos \theta_{1}\right), \\
& \mu_{2}=\mu\left(\sin \theta_{2} \cos \varphi_{2}, \sin \theta_{2} \sin \varphi_{2}, \cos \theta_{2}\right),
\end{aligned}
$$

where $\mu$ is the magnitude of a monomer dipole. The vector sum law holds in short time scale and gives the instantaneous dipole $\mu_{1}+\mu_{2}$ for the dimer as

$$
\mu_{1}+\mu_{2}=\mu\left(\sin \theta_{1} \cos \varphi_{1}+\sin \theta_{2} \cos \varphi_{2}, \sin \theta_{1} \sin \varphi_{1}+\sin \theta_{2} \sin \varphi_{2}, \cos \theta_{1}+\cos \theta_{2}\right),
$$

When the monomer-monomer interaction is very strong, $\theta_{2}$ and $\varphi_{2}$ can be expressed in terms of $\theta_{1}$ and $\varphi_{1}$ as

$$
\theta_{2}=\pi-\theta_{1}, \quad \text { and } \quad \varphi_{2}=\varphi_{1} \text {. }
$$

In this case the dimer has no averaged dipole:

$$
\left\langle\mu_{1}+\mu_{2}\right\rangle=0,
$$

where \langle\rangle denotes the average over a long period. When the monomer-monomer interaction is very weak, $\theta_{1}, \theta_{2}, \varphi_{1}$, and $\varphi_{2}$ are independent variables, and the average of the dimer dipole is expressed in terms of the sum of the individual monomer dipoles as

$$
\left\langle\mu_{1}+\mu_{2}\right\rangle=\left\langle\mu_{1}\right\rangle+\left\langle\mu_{2}\right\rangle \text {, }
$$

where an electric field interacts with the dipole of the monomer. The real state of the substance is in the intermediate between monomer and dimer. The correlated motions in the dimer are disturbed with random forces from surroundings. To express the non-correlated portion of the monomer movement in eq 2 , we introduce the random variables $\delta$ and $\varepsilon$ as the phase shifts of angles :

$$
\theta_{2}=\pi-\left(\theta_{1}+\delta\right) \quad \text { and } \quad \varphi_{2}=\varphi_{1}-\varepsilon
$$


The phase shifts in the dipole motion are caused by the disturbance of random forces. These phase shifts serve as the measure of the monomeric character in the dimer and of the strength of disturbance. The large phase shifts denote a strong disturbance and a dominant monomeric character. These phase shifts are introduced as paraneters, though these can in principle be calculated from the correlation function between two monomers. Since the monomer-monomer interaction is considerably strong in comparison with the disturbance, the phase shifts $\delta$ and $\varepsilon$ are assuned to be small. The insertion of eq 3 into eq 1 gives the instantaneous dipole of

$\mu_{1}+\mu_{2}=\mu(\sin \theta \cos \varphi+\sin (\theta+\delta) \cos (\varphi-\varepsilon), \sin \theta \sin \varphi+\sin (\theta+\delta) \sin (\varphi-\varepsilon), \cos \theta-\cos (\theta+\delta))$ $\leftrightharpoons \mu(2 \sin \theta \cos \varphi+\delta \cos \theta \cos \varphi+\varepsilon \sin \theta \sin \varphi, 2 \sin \theta \sin \phi+\delta \cos \theta \sin \varphi-\varepsilon \sin \theta \cos \varphi, \delta \sin \theta)$

In eq 4 and hereafter the subscripts of angular variables for the monomer 1 were omitted $\left(\theta_{1} \rightarrow \theta, \varphi_{1} \rightarrow \varphi\right)$. The dipole instantaneously induced with atomic motions in the dimer do not cause a dielectric relaxation. The average of the dipole moment of eq 4 should be non-zero to cause the dielectric relaxation. A dielectric relaxation is observed only when the life span of dipole is sufficiently long in comparison with the time scale of the atomic motion. A dielectric relaxation can be caused by the dipole of which life is longer than at least $10^{-1}-10^{-2}$ times the relaxation time. The average of dipole moment for one dimer can be calculated on the assumption that $\delta$ and $\varepsilon$ are constant for the time interval to take an average. The average $m$ of a dipole is

$$
\begin{aligned}
m_{x, y, z} & =\left\langle\mu_{1}+\mu_{2}\right\rangle_{x, y, z} \\
& =\left\{\int_{-\pi}^{\pi} \mathrm{d} \varphi \int_{0}^{\pi} \exp \left(-U / k_{B} T\right)\left(\mu_{1}+\mu_{2}\right)_{x, y, z} \sin \theta \mathrm{d} \theta\right\} /\left\{\int_{-\pi}^{\pi} \mathrm{d} \varphi \int_{0}^{\pi} \exp \left(-U / k_{B} T\right) \sin \theta \mathrm{d} \theta\right\},
\end{aligned}
$$

where $k_{B}$ is the Boltzman constant, $T$ temperature, and $U$ the potential for the angular motion of the dipole. The potential $U$ is assuned to be given in terms of the sum of the harmonic potential of bending and the periodic one of the rotation: 


$$
U=\frac{A \theta^{2}}{2}+\frac{1+\cos (2 \theta)}{2} V_{0}
$$

Where $A$ denotes the force constant of bending motion for the dipole and $V_{0}$ a barrier of rotation. It is easily proved that the $x$ and $y$ component of a dipole are zero in the evaluation of eq 5 with the potential of eq 6 . Thus the average value of a dipole is given as

$$
m_{x}=0, \quad m_{y}=0, \quad m_{x}=\mu \delta B
$$

where

$$
\begin{aligned}
B & =\left\{\int_{-\pi}^{\pi} \mathrm{d} \varphi \int_{0}^{\pi} \exp \left(-U / k_{B} T\right) \sin ^{2} \theta \mathrm{d} \theta\right\} /\left\{\int_{-\mathbf{z}}^{\pi} \mathrm{d} \phi \int_{0}^{\pi} \exp \left(-U / k_{B} T\right) \sin \theta d \theta\right\} \\
& =\left\{\int_{0}^{\pi} \exp \left(-A \theta^{2} / 2 k_{B} T\right) \sin ^{2} \theta \mathrm{d} \theta\right\} /\left\{\int_{0}^{\pi} \exp \left(-A \theta^{2} / 2 k_{\mathrm{B}} T\right) \sin \theta \mathrm{d} \theta\right\} .
\end{aligned}
$$

The value of $B$ was numerically calculated as shown in Table $\mathbf{I}$. The $B$ value was found to depend on $A / 2 k_{B} T$ in some extent, but not on the barrier $V_{0}$ of rotational potential and the phase shift $\varepsilon$. The dipole of the dimer unit results from the difference between two monomer dipoles. The components perpendicular to the $z$ axis are averaged out to zero because of the speedy motions of there components. The dipole is oriented in the direction of the $z$ axis. The dipole moment is proportional to the phase shift $\delta$, which specifies the monomeric character and the disturbance strength. It is easily shown that the dipole of the dimer is caused by the non-alternation of signs of the phase shift $\delta$ for averaging, where the assumption of the constant phase shift is not necessarily required. The life of the dipole is considered to be the period for the non-alternation of signs of $\delta$. The direction of the dipole is constant and the magnitude of the dipole as well as $\delta$ changes with time.

We define the space-fixed coordinates as a parallel shift of the molecule-fixed. The direction of the dipole in laboratory frame has an advantage to observe the dielectric relaxation, since the crystalline c-axis which is the approximate 
direction of the dipole seem to be nearly parallel to the electric field considering the strong (00l) X-ray reflections. The electric field crosses the dipole at a small angle. The calculated monents of dimer units distribute according to the distribution of $\delta$. We assume that the probabilities $P_{b}$, where the phase shift for one dimer is $\delta$, is given by the Gaussian distribution as,

$$
P_{\hat{\delta}}=1 /\left((2 \pi)^{1 / 2} \delta_{0}\right) \exp \left(-\delta^{2} / 2 \delta_{0}^{2}\right) \text {, }
$$

where $\delta_{0}$ is the standard deviation of $\delta$. The average $|m|$ of the dipole moment is estimated for an ensemble of dimers as

$$
|m|=(2 / \pi)^{1 / 2} \mu \delta_{0} B .
$$

In this model $\delta_{0}$ as vell as the dipole moment $|w|$ of the dimer increase with temperature, while the dipole moment $\mu$ of a monomer and $B$ are almost independent of temperature change. The calculated temperature dependence of the dipole moment agrees qualitatively with the experimental results. In Figures $1-3$ the location of loss maximum shifts to higher frequencies with temperature, suggesting that the life of the dipole is shorter at higher tenperatures.

Now we roughly estimate the dipole moment of this model. Since the bond monent for $\mathrm{OH}$ or $\mathrm{O} \cdots \mathrm{H}$ is dominant for the dipole of a dimer, the force constant $\mathrm{A}$ of bending motion for the dipole ( see eq 6) can be approximated by coefficient $k r_{\text {OHrn...H }}$ of the $\mathrm{OH}$ out-of-plane bending motion. The force constant $k$ was given by Umemura ${ }^{19}$ as $0.042 \mathrm{mdynA}^{-1} \mathrm{rad}^{-2}$ and the distance $r_{0 \mathrm{H}}$ and $r_{0 \ldots H}$ are 1.0 and $1.64 \mathrm{~A}$, respectively. ${ }^{20}$ The temperature where the dielectric relaxation was observed is about $200 \mathrm{~K}$ and the value of $A / 2 k_{B} T$ is about 12.5 so that $B=0.244$. To estimate the phase shift $\delta_{0}$, the probable bending angle $\theta$ was estimated to be 0.3 radian from the relation: $k_{0 \mathrm{Br}} r_{0} \ldots \theta^{2} / 2 k_{B} T=1$. Thus $\delta_{0}$ is 0.3 radian at most and the actual phase shift is probably about $\delta_{0}=0.1$ radian. The value of $1.74 \mathrm{D}$ for the dipole moment $\mu$ of the monomer unit is adopted from the data for the stearic acid in dioxane solution. ${ }^{21}$ Then the average moment is calculated as $|m|=0.034 \mathrm{D}$. We compare the estimated dipole moment with the experimental one in Table I, though 
this dipole was calculated on the proposed model while the experimental one by Onsager's equation. The agreement of these two values is reasonable. As discussed above, the centrosymmetric dimer can have a dipole. The vector sum law holds only in the short time interval but not in the averaged dipole.

Difference of Odd from Even Numbered Acids. The dielectric relaxations caused by the dipole were observed in the low temperature phase of odd numbered acids, while not in the high temperature phase $C^{\prime}$ of odd numbered acids and not in the even numbered acids. The dipole moment discussed in the preceding paragraph is determined by a single parameter $\delta$ defining the phase shift. The large phase shift yields the dipole large enough to detect. The small phase shift yields the dipole too small to detect in the even numbered acids and in the high temperature phase of odd numbered acids. The dipole moment observed in the lov temperature phase of odd numbered acids is due to the weak monomer-monomer interaction( i.e. a large phase shift). The monomer-monomer interaction in the dimer unit can be a sole function of the strength of hydrogen bond. The strength of hydrogen bond has been investigated by many infra-red studies. The $\mathrm{OH}$ out-of-plane bending notion at $80 \mathrm{~K}$ locates at ${ }^{22}$ 960-980 $\mathrm{cm}^{-1}$ for even numbered acids and the super-cooled $C^{\prime}$-form of undecanoic acid while at $\mathrm{t}^{23}$ about $885 \mathrm{cns}^{-1}$ for the odd numbered acids of low temperature phase ( $B^{\prime}$ for undecanoic and pentadecanoic acids and $A^{\prime}$ for tridecanoic acid ). The wavenumbers for the odd numbered acids are about $90 \mathrm{~cm}^{-1}$ lower than those for the even numbered acids. These lov wavenumbers suggest ${ }^{24}$ that the hydrogen bond in the low temperature phase of the odd numbered acid is weaker than that of even numbered acid. The crystal field and the interaction with neighboring dimer affect the strength of the hydrogen bond and the phase shift. The dimer of weak hydrogen bond yields the independent motion of the individual monomers. The field which reakens the hydrogen bond gives a large phase shift. The phase shift $\delta$ in the low tenperature crystalline phase of odd numbered acids are large enough to observe the 
dielectric relaxation whereas not in the even numbered acids. The large difference in imaginary parts of permittivity for pentadecanoic acid from undecanoic and tridecanoic acids is the object for future studies.

The thermal hysteresis loops seen in Figures 4-9 suggest that the cooling or heating rate are too fast to observe the equilibrium permittivity. The dispersion of the Curie-von Schweidler law observed around $300 \mathrm{~K}$ for six compounds may be caused by space charge effects but is not discussed here, because this dispersion has no relation with the dielectric relaxation in question.

Acknowledgment. The author wishes to express his gratitude to Professor Eneritus N. Koizumi, Professor T, Hanai, Dr. S. Hayashi and Dr. K, Kajiwara for their heartfelt encouragement and valuable discussions. 
Reference

(1) Uehara, K.; Sakurai K.; Shimoda, K. J. Phys. Sac. Jpn. 1969, 26, 1018.

(Z) Luntz, A. C.; Brewer, R, G, J. Chem, Phys. 1971, 54, 3641.

(3) Mizushima, M.; Venkateswarlu, P. J. Chem. Phy. 1053, 21, 705.

(4) Mills, I. M.; Watson, J. K. G.; Smith W. L. Mol. Phys. 1989, 16, 329.

(5) Sinyth, C. P.; Rogers, H. E. J. Amer, Chen. Soc. 1930, 52, 1824.

(6) Harris, F. E.; Alder, B. J. J. Chem. Phys, 1953, 21, 1306.

(7) Loveluck, G. J. Phys, Chent. 1900, 64, 385.

(8) Sydow, E. ARKIV FOR KENI 19569 , 231.

(9) Goto, M.; Asada, E. Bull. Chem. Soc. Jpn. 1980, 53, 2111.

(10) Kondo, S.; Oda, T. Bull. Crem. Soc. Jpn. 1954, 27, 567.

(11) MoCamon, R. D.; Work, R. N. Rev. Sci. Instr. 1965, 36, 1169.

(12) Kita, Y.; Koizumi, N, Bull. Inst. Chen. Res. Kyoto Univ. 1965, 63, 249.

(13) Kita, Y.; Koizumi, N. Adv. Mol. Relax. Interaction Processes 1979, 15, 261.

(14) Bottcher, C. J. F. revised by van Belle, O. C.; Bordevijk, P.; Rip, A.

Theory of Electric Polarization; Elsevier; Ansterdam, 1973; p 178.

(15) Sydow, E. Acta Cryst, 1955, 8, 810.

(16) Schweidler, E. Ann. Phys. 1907, 24, 711.

(17) Gough, S. R. Mol. Cryst. Liq. Cryst, Lett 1981, 64, 269.

(18) Sinyth, C. P. Dielectric Behavior and Structure

(MoGraw-Hill, New York, 1955), p. 171.

(19) Utwernura, J. J. Chem. Phys. 1978, 68, 42.

(20) Feld, R.; Lehmann, M. S.; Muir. K. W.; Speakman, J. C. Z. Kristal lograph, $1981157,215$.

(21) Wilson, C, J.; Wenzke, H, H, J. Chem. Phys, 1934, 2, 546.

(22) Hayashi, S.; Umemura, J. J. Chem. Phys. 1975, 63, 1732.

(23) Holland, R. F. ; Nielsen, J. R. Acta Cryst. 1963, 16, 902.

(24) Novak, A., Strweture and Bonding 1974, 18, 177. 
TABLE I: Relaxation intensities and the dipole moment of fatty acid dimer on the essumption of the Onsager fields. The densities of acids were taken as $1 \mathrm{gcm}^{-3}$ in eccordance with the Sydow's ralue 15 of 1.02 of undecanoic acid at $23{ }^{\circ} \mathrm{C}$.

\begin{tabular}{lccccccc}
\hline \multicolumn{3}{c}{ undecanoic acid } & & \multicolumn{3}{c}{ tridecanoic acid } \\
\cline { 7 - 8 } temp. $/ \mathrm{K}$ & $\Delta \varepsilon / 10^{-3}$ & $\mu / \mathrm{D}$. & & temp. $/ \mathrm{K}$ & $\Delta \varepsilon / 10^{-3}$ & $\mu / \mathrm{D}$. \\
\hline 202.1 & 11 & 0.15 & & 147 & 2.8 & 0.07 \\
208.5 & 12 & 0.16 & & 160 & 3.9 & 0.08 \\
212.4 & 12 & 0.16 & & 177 & 5.2 & 0.10 \\
216.9 & 13 & 0.17 & & 190 & 5.9 & 0.11
\end{tabular}

TABLE II: B value for several potential parameter.

\begin{tabular}{cccccccc}
\hline$A / 2 k_{B} T$ & 7.5 & 10 & 12.5 & 15 & 17.5 & 20 & 25 \\
$B$ & 0.310 & 0.271 & 0.244 & 0.224 & 0.208 & 0.195 & 0.175
\end{tabular}


Figure captions

Figure 1. Imaginary parts of relative permittivities for the $B^{\circ}$-form of undecanoic acid against frequency. The temperature maintained is indicated in the figure. The difference between cooling and heating processes was not observed within an experimental error. The measurements were carried out with the Ando TR-10 transformer bridge.

Figure 2. The same as in Figure 1 for the $A^{\prime}$-form of tridecanoic acid.

Figure 3. The same as in Figure 1 for the $B^{\prime}$-form of pentadecanoic acid. The measurements were carried out with the GR-1616 transformer bridge. The loss maximum for the relaxation was indicated by the arrow.

Figure 4. Real parts of relative permittivities for the $B^{\prime}-$ and $C^{\prime}$-form undecanoic acid against temperature. The process of cooling or heating and the frequency are denoted in the figure.

Figure 5. The same as in Figure 4 for the $A^{\prime}-$ and $C^{\circ}$-form of tridecanoic acid.

Figure 6. The same as in Figure 4 for the $B^{\prime}-$ and $C^{\prime}$-form of pentadecanoic acid.

Figure 7. The same as in Figure 4 for the $C$-form of lauric acid.

Figure 8 . The same as in Figure 4 for the C-form of myristic acid.

Figure 9. The same as in Figure 4 for the C-form of palmitic acid. 
Figure 10. The dipole direction at an instant in the molecule(dimer)-fixed coordinates. Capital letters of $\mathrm{C}, \mathrm{H}$, and $\mathrm{O}$ denote the average positions of atons. The large size letter means forward the plane of the paper and the small size behind. All carbon and oxygen atoms are in the $x-z$ plane on the average. The space-fixed coordinates are the parallel shift of the molecule-fixed. The $z$-axis denoted with dotted broken line is parallel to the averaged direction of the monomer dipole and a broken line is parallel to the c-axis in crystal. 


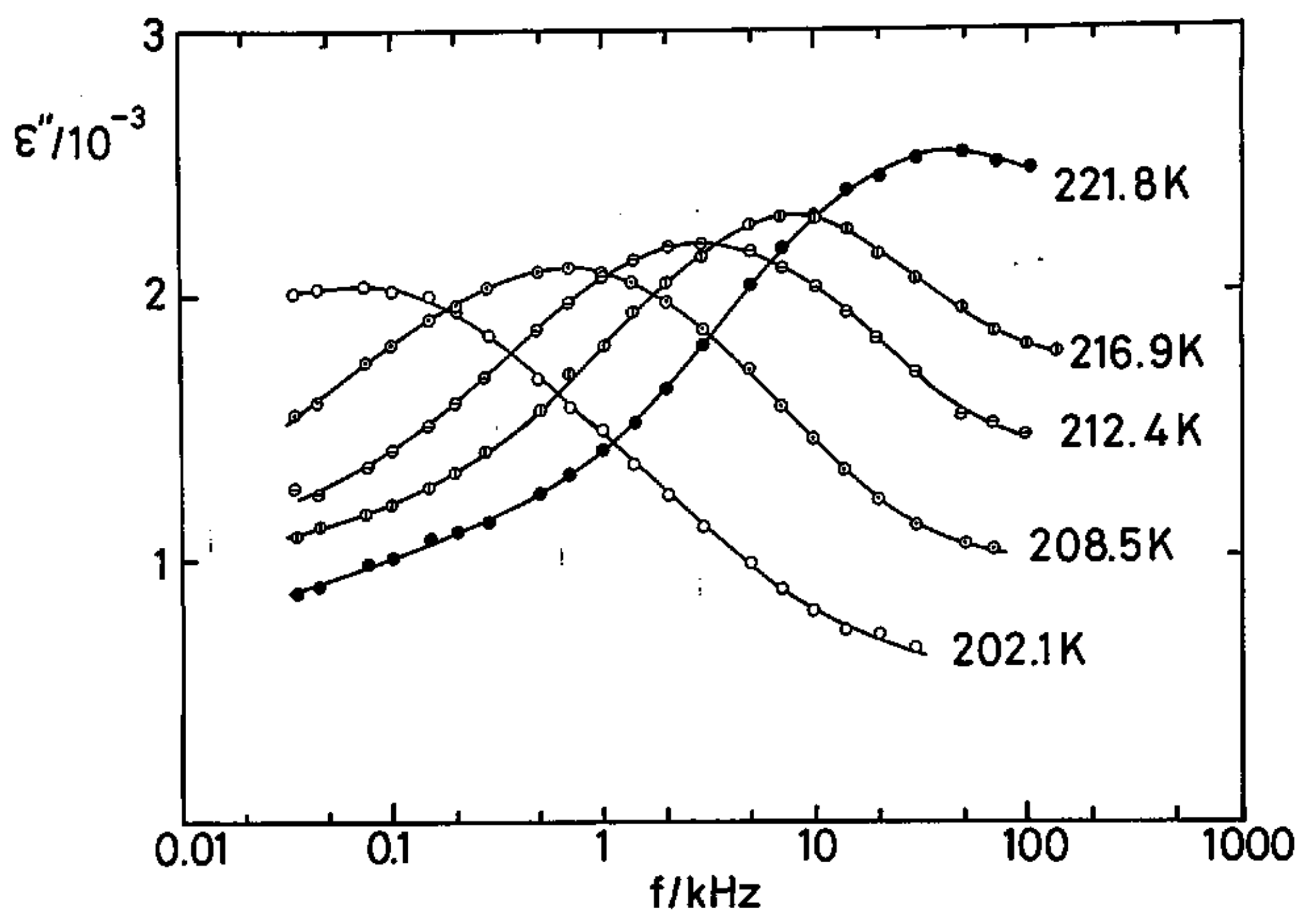




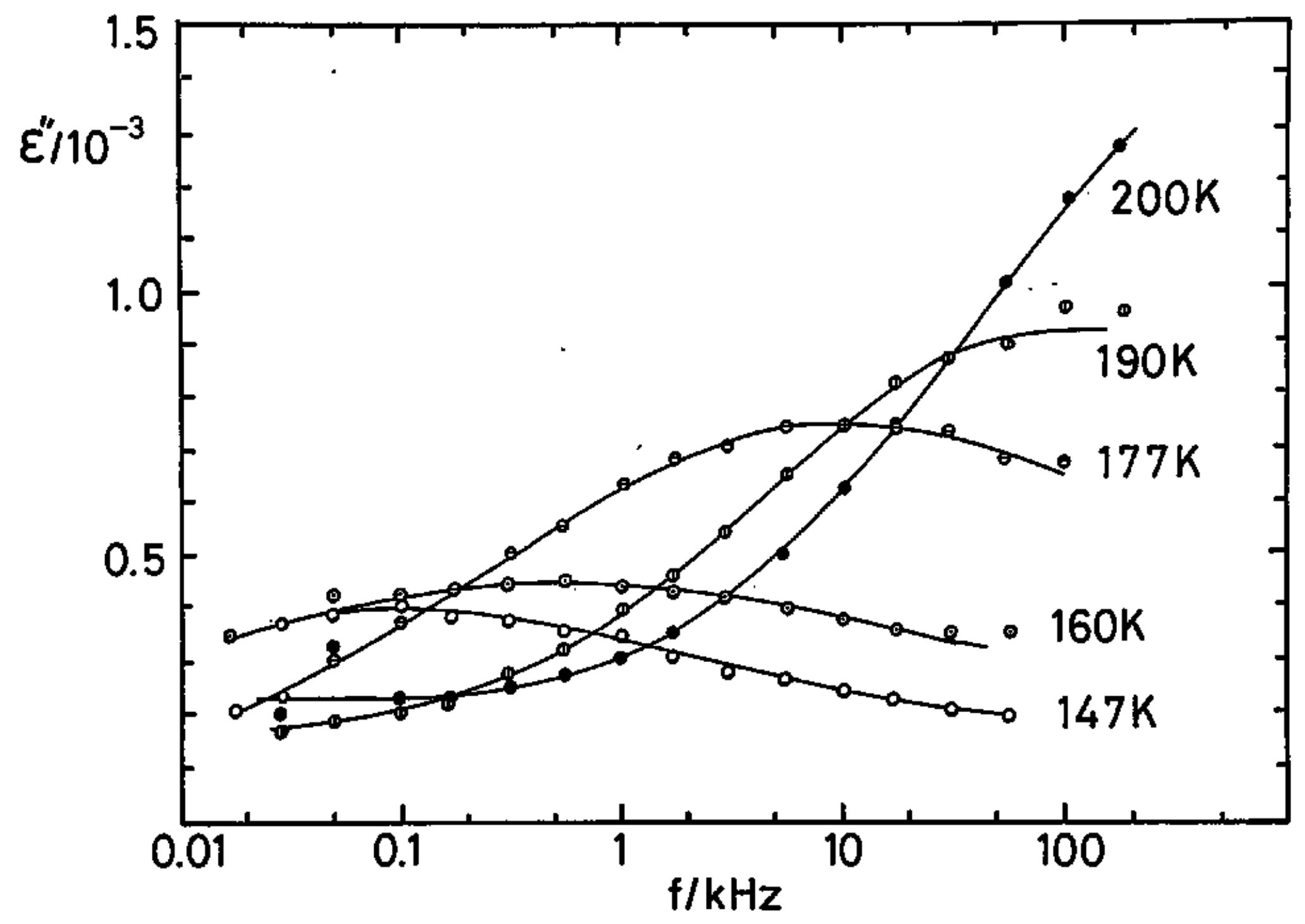




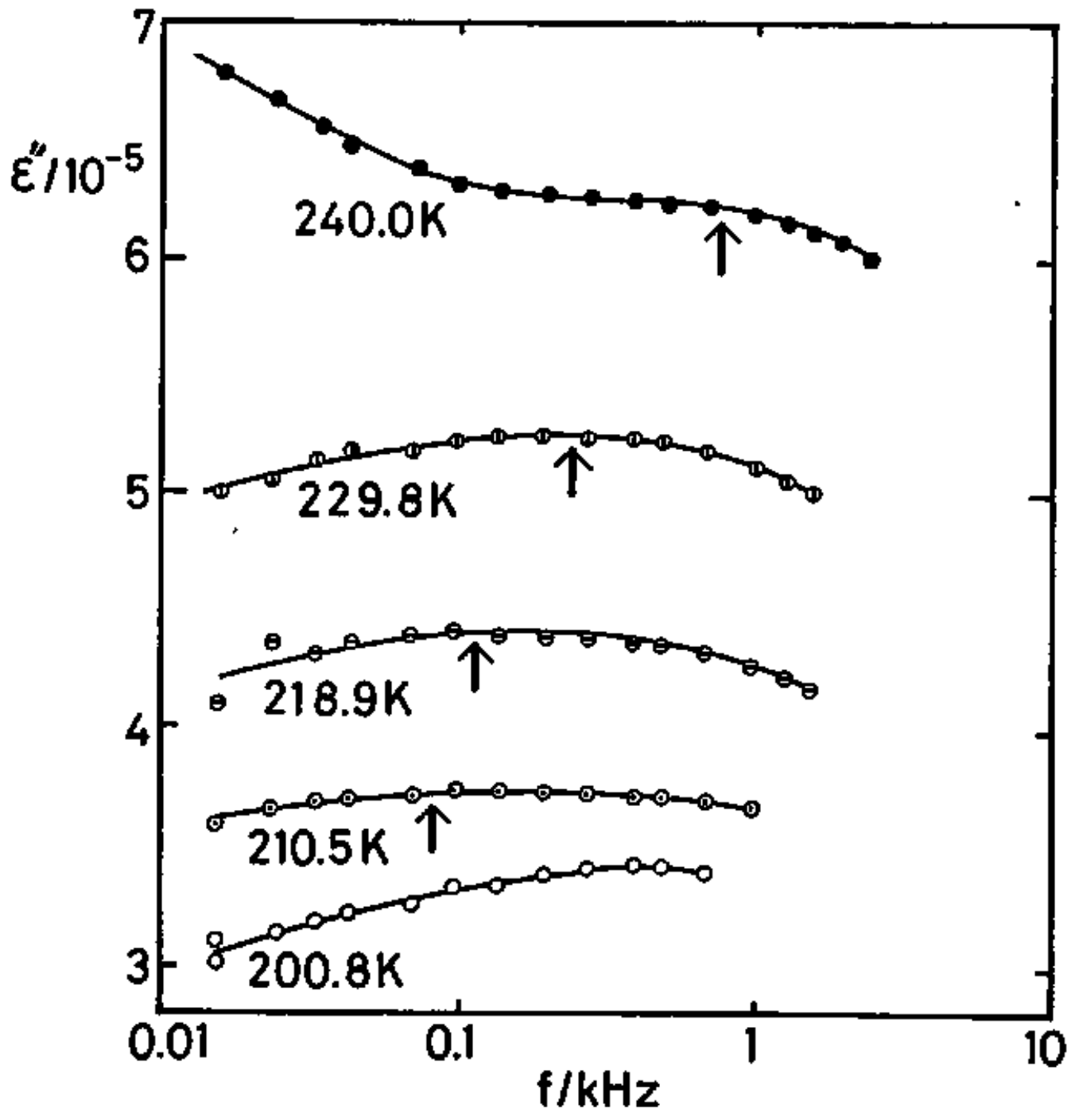




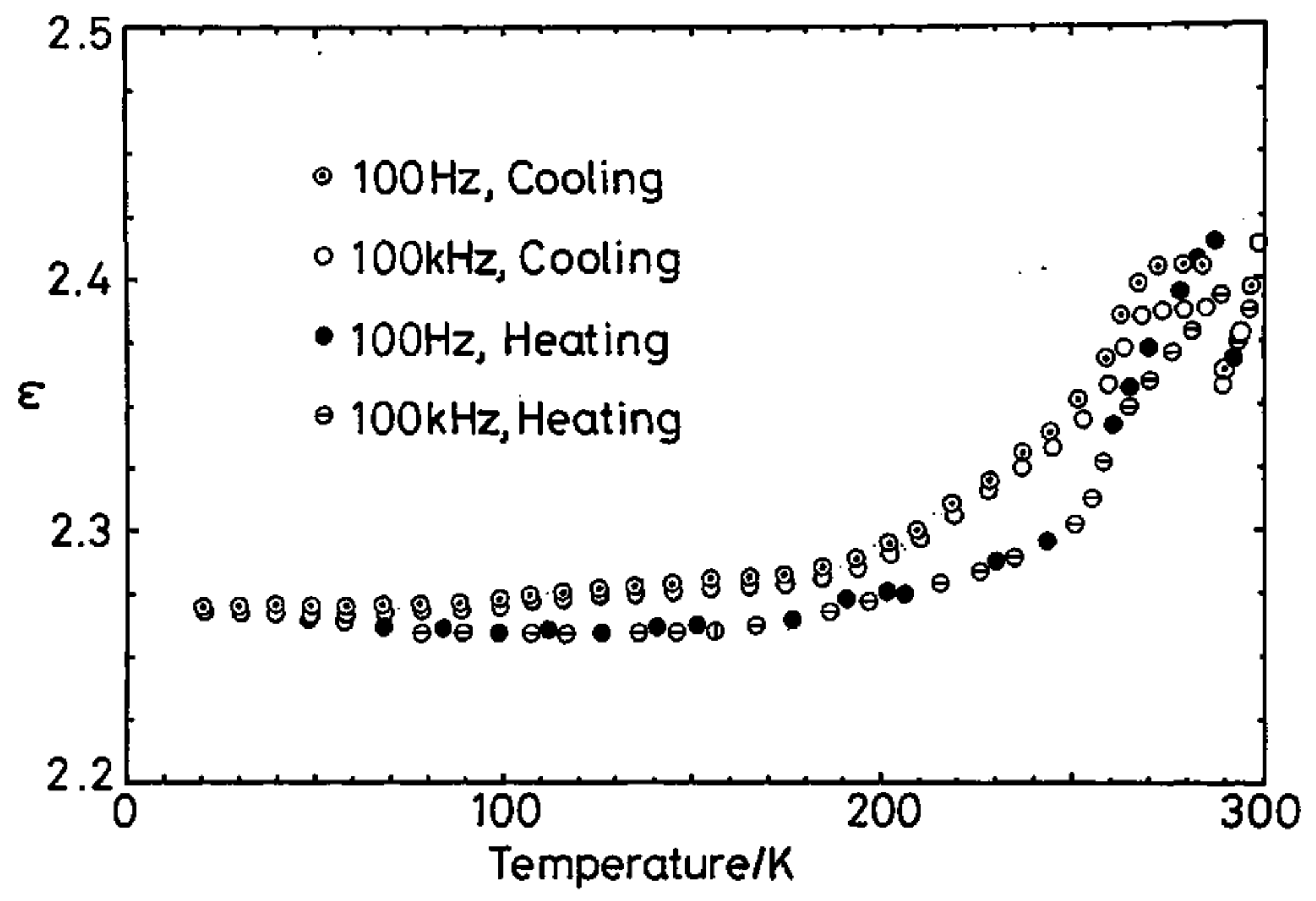




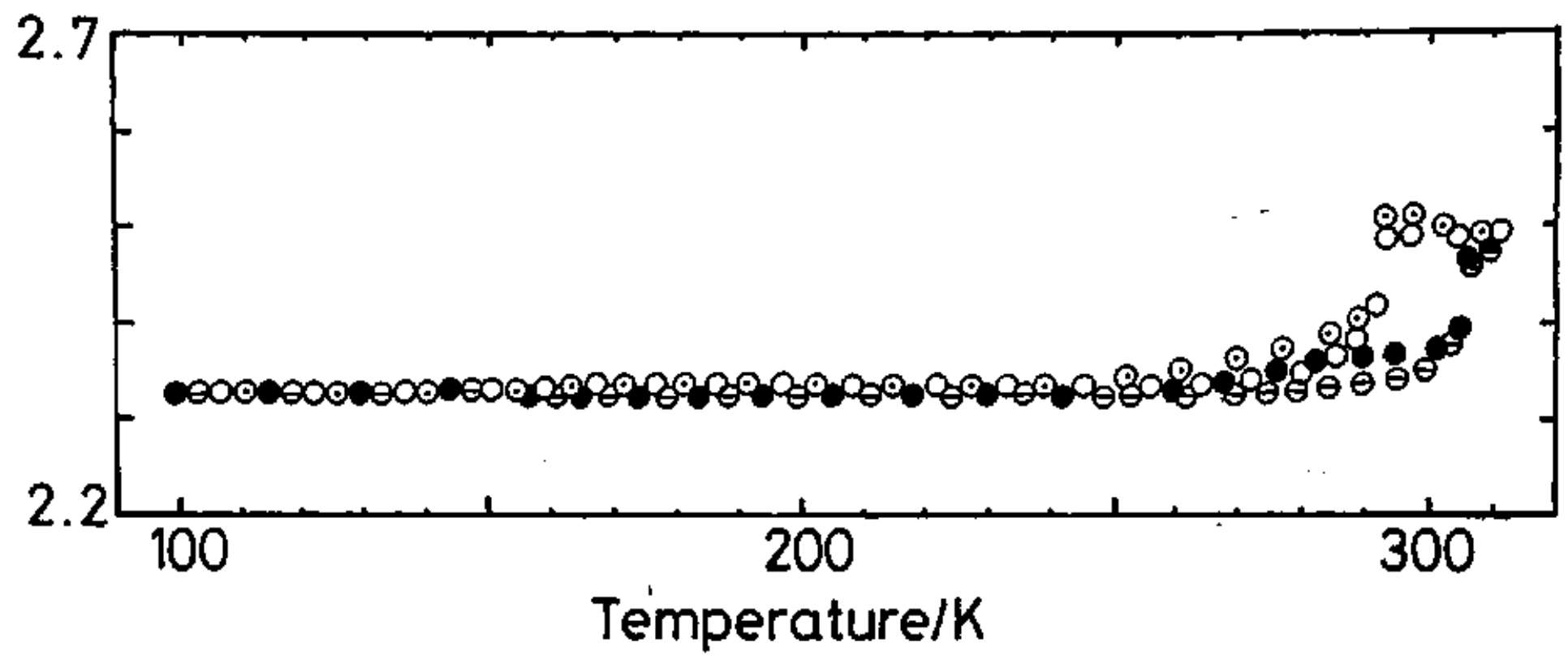




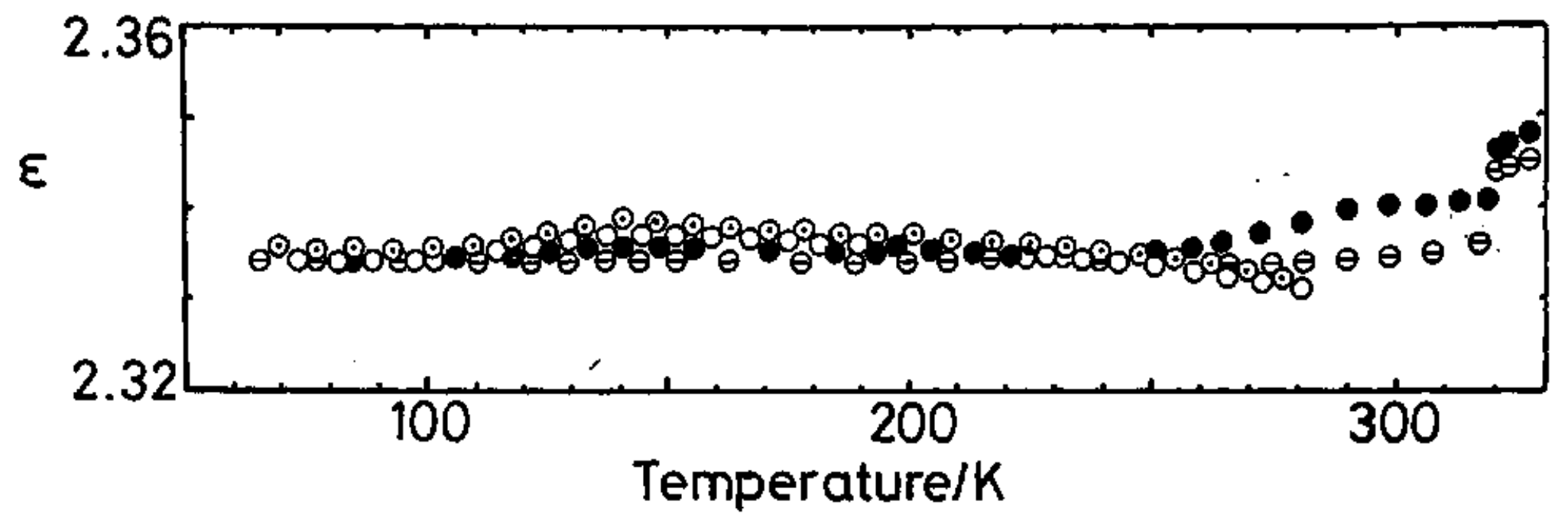




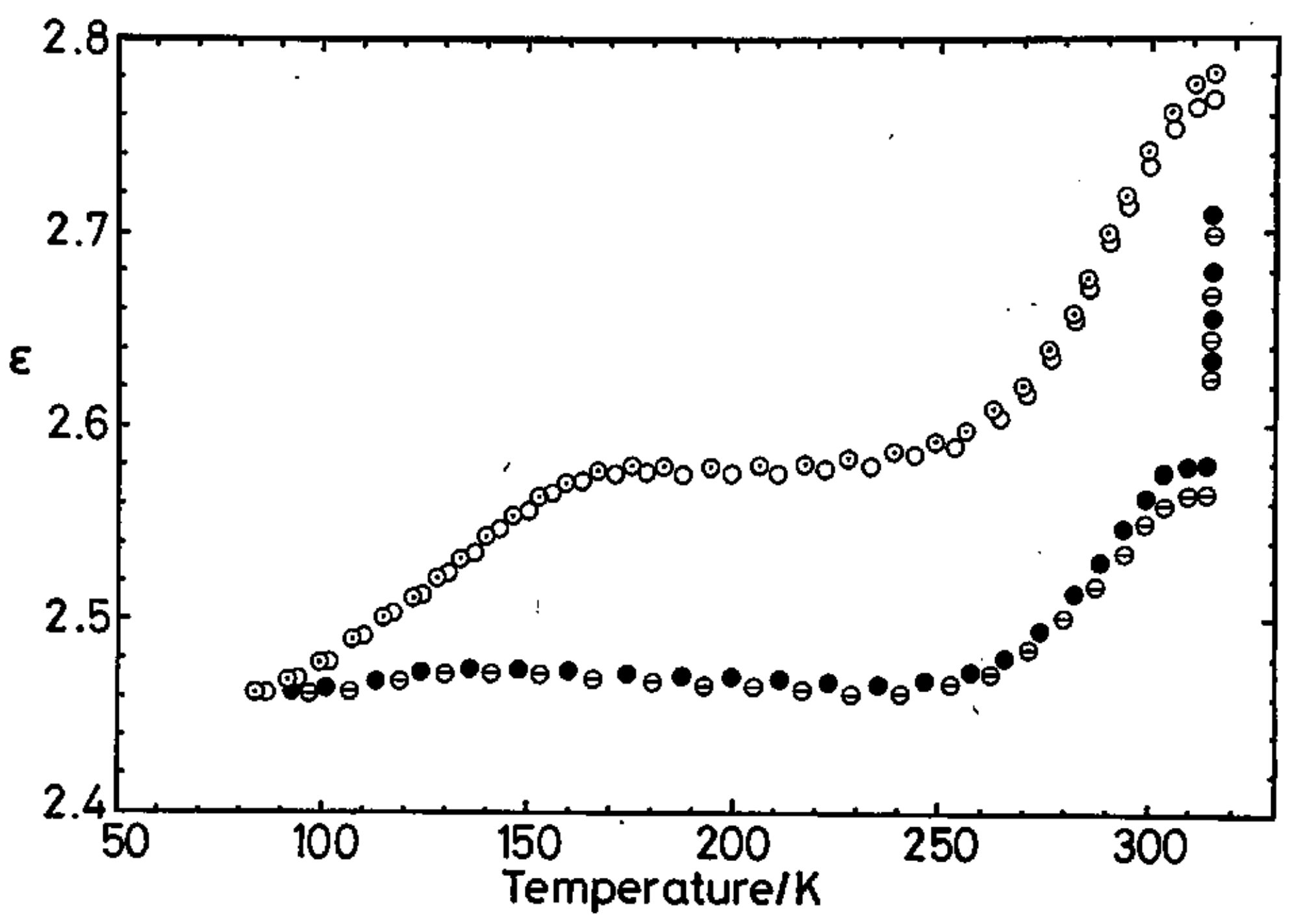




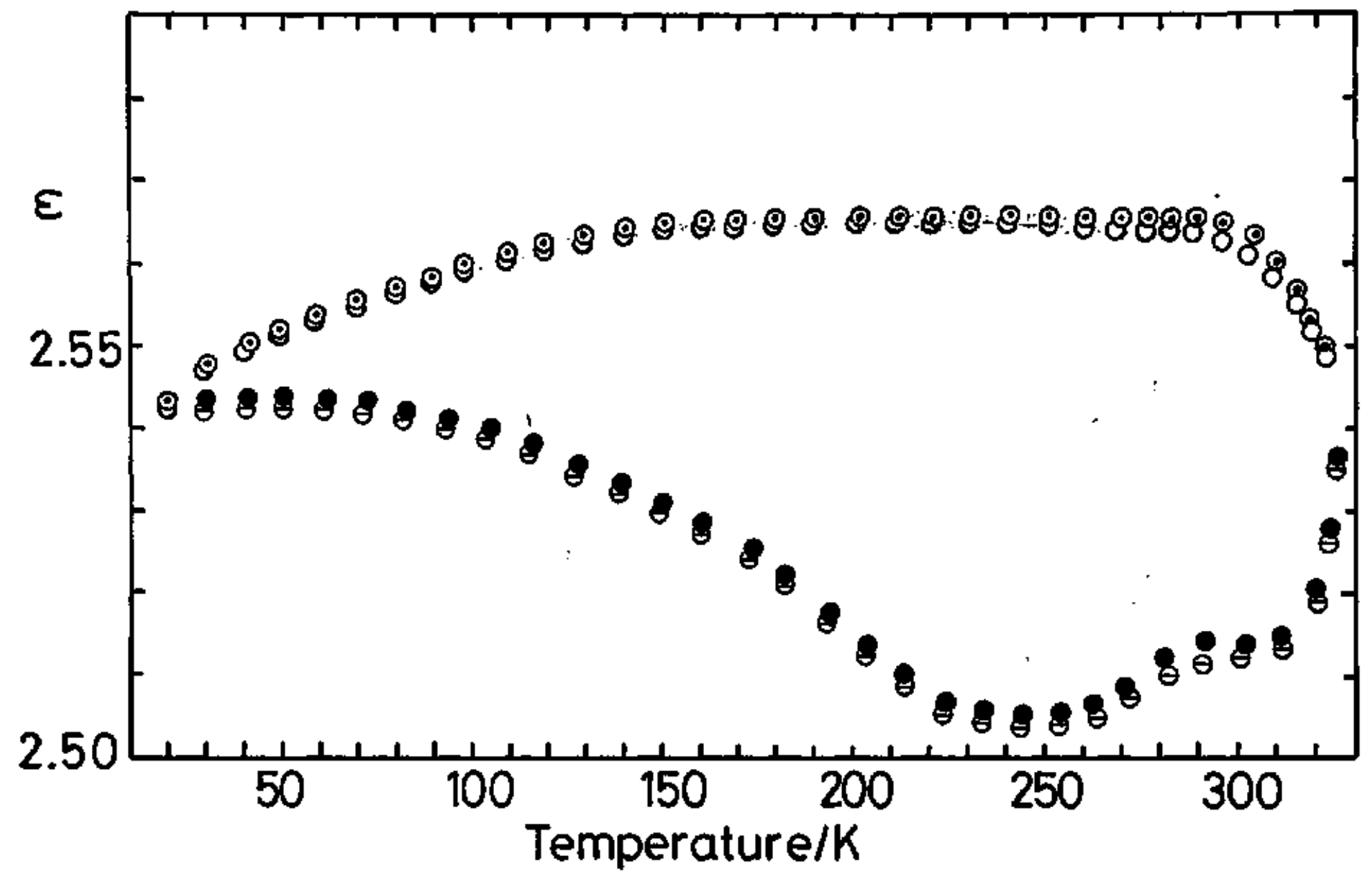




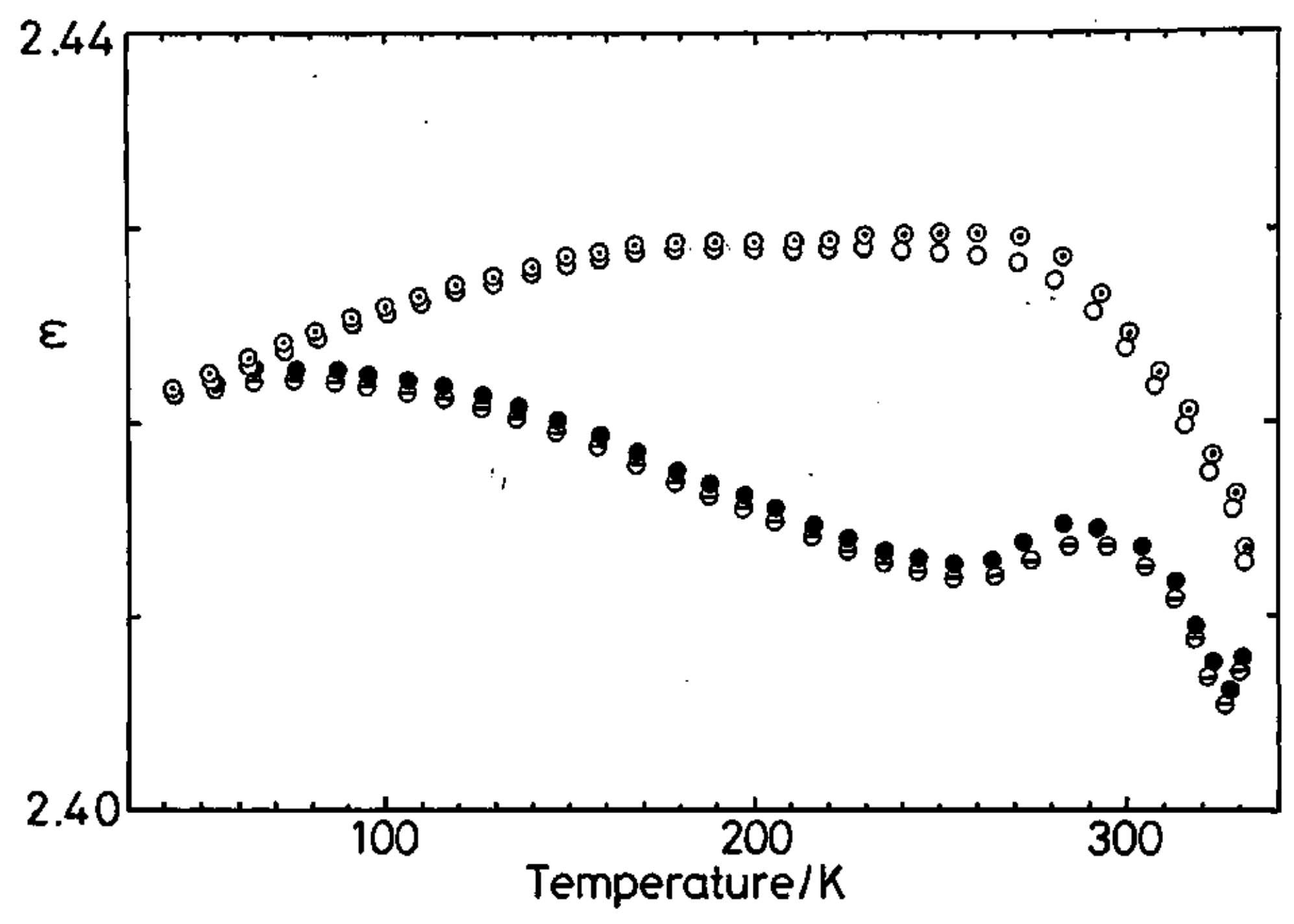




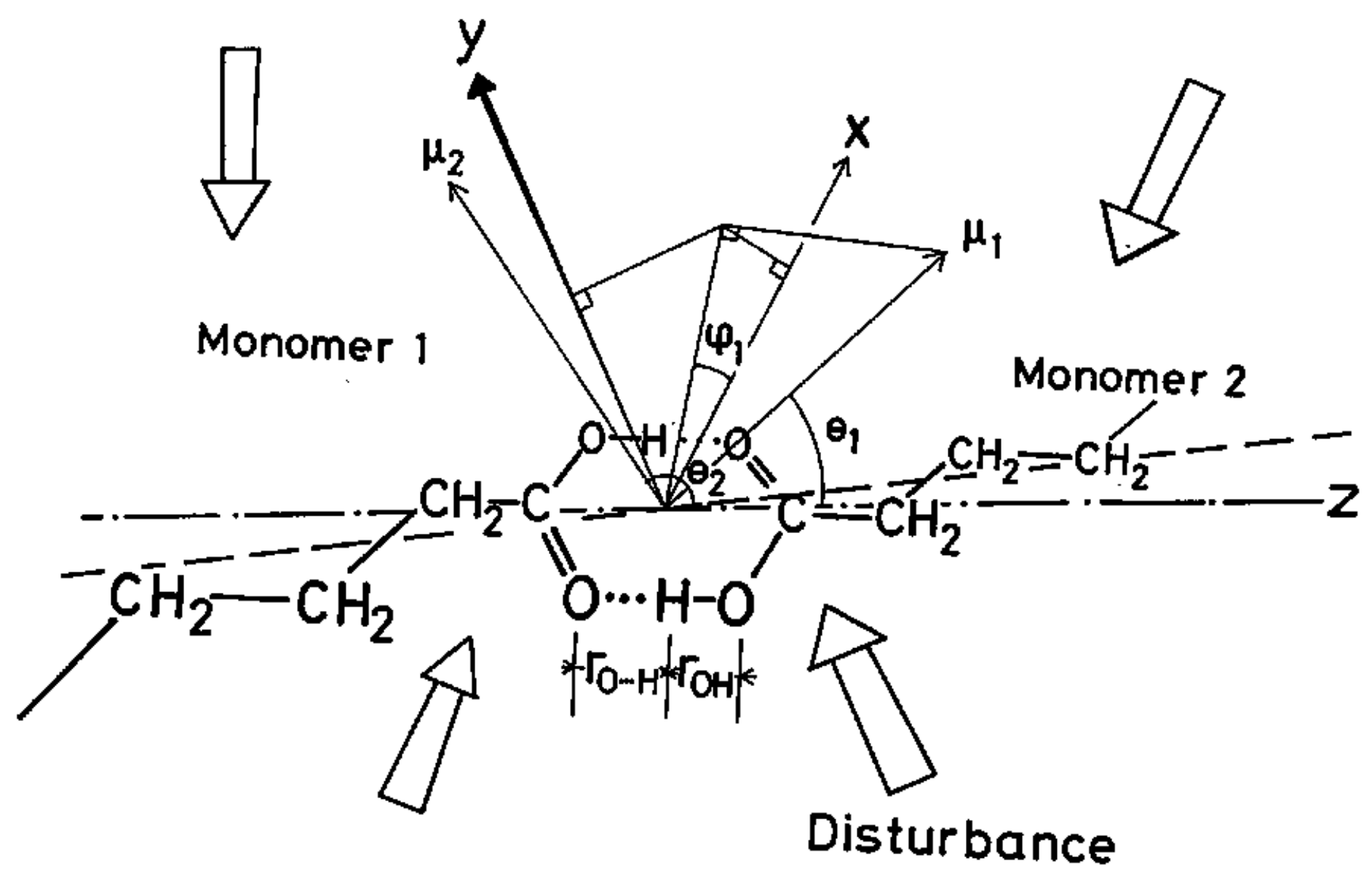

